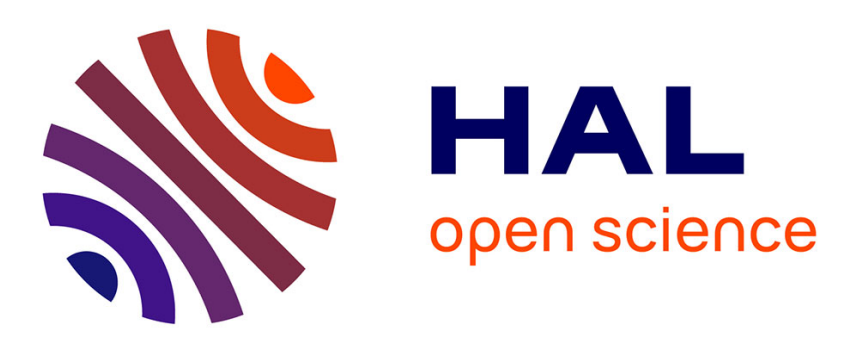

\title{
Anxiety during tests and regulatory dimension of anxiety: A five-factor French version of the Revised Test Anxiety scale
}

\author{
Nicolas Mascret, Sarah Danthony, François Cury
}

\section{To cite this version:}

Nicolas Mascret, Sarah Danthony, François Cury. Anxiety during tests and regulatory dimension of anxiety: A five-factor French version of the Revised Test Anxiety scale. Current Psychology, 2021, 40 (11), pp.5322 - 5332. 10.1007/s12144-019-00481-w . hal-03545051

\section{HAL Id: hal-03545051 \\ https://hal.science/hal-03545051}

Submitted on 27 Jan 2022

HAL is a multi-disciplinary open access archive for the deposit and dissemination of scientific research documents, whether they are published or not. The documents may come from teaching and research institutions in France or abroad, or from public or private research centers.
L'archive ouverte pluridisciplinaire HAL, est destinée au dépôt et à la diffusion de documents scientifiques de niveau recherche, publiés ou non, émanant des établissements d'enseignement et de recherche français ou étrangers, des laboratoires publics ou privés. 
Anxiety during tests and regulatory dimension of anxiety: a five-factor French version of the Revised Test Anxiety scale

First author (corresponding author):

Mascret Nicolas

Aix Marseille Univ, CNRS, ISM, Marseille, France

163 avenue de Luminy, Case 910, 13288 Marseille cedex 9

SFERE-Provence, FED 4238, Marseille, France

Email: nicolas.mascret@univ-amu.fr

$+33618022983$

Second author:

Danthony Sarah

Aix Marseille Univ, CNRS, ISM, Marseille, France

163 avenue de Luminy, Case 910, 13288 Marseille cedex 9

Email: sarahdanthony@gmail.com

Third author:

Cury François

Aix Marseille Univ, CNRS, ISM, Marseille, France

163 avenue de Luminy, Case 910, 13288 Marseille cedex 9

Email : francois.cury@univ-amu.fr 


\begin{abstract}
Test anxiety is considered a performance-debilitating form of anxiety. Worry, test-irrelevant thinking, tension, and bodily symptoms are the four components of test anxiety which are measured through the Revised Test Anxiety (RTA) scale (Benson \& El-Zahhar, 1994). All these components represent negative dimensions of test anxiety. The aim of the study is twofold: (1) to test the factorial, convergent, discriminant, and predictive validity of a French version of the four-factor initial RTA scale, and (2) to expand it with an original fifth subscale representing the regulatory dimension of anxiety (namely perceived control), underlying its adaptive potential. 403 students (201 girls) from French collèges (ages 13-15) and lycées (ages 15-18) completed a series of questionnaires. The results indicate that the five-factor model of the French Revised Test Anxiety + Regulatory scale (FRTA+R) is supported by a Confirmatory Factor Analysis. Convergent validity and discriminant validity of the scale are also attested. Achievement goals and general school self-esteem are found to be significant predictors of the five factors of test anxiety. This upgraded scale now provides additional information to better understand test anxiety in an educational context, especially in the French context in which students often experience high levels of test anxiety.
\end{abstract}

Keywords: anxiety, achievement goals, self-esteem, perceived control, stress 
Anxiety during Tests and the Regulatory Dimension of Anxiety: A Five-factor French Version of the Revised Test Anxiety scale

Test anxiety is a major educational concern and an important focus of research in educational psychology. Many well-established scales already exist to assess this construct. However, this literature in the French academic context is very underdeveloped and a validated scale is lacking (e.g., Cury, Da Fonseca, Zahn, \& Elliot, 2008). Furthermore, test anxiety is mainly defined as a negatively-toned emotion (e.g., Putwain \& Symes, 2012; Rost \& Schermer, 1992), but some models have shown that anxiety may also have an adaptive capacity directly included in the dynamic of anxiety (e.g., Cheng, Hardy, \& Markland, 2009; Eysenck, Derakshan, Santos, \& Calvo, 2007, Nieuwenhuys \& Oudejans, 2012). Consequently, the aim of this study is twofold: to develop a French version of the well-known Revised Test Anxiety (RTA) scale (Benson \& ElZahhar, 1994) and to examine the potential benefits of including in this scale a new component, namely the regulatory dimension of anxiety, represented by perceived control. Extending the original Revised Test Anxiety scale with the perceived control component provides the opportunity to investigate the adaptive potential of test anxiety (Cheng et al., 2009), which remains largely unexplored in the test anxiety literature.

\section{Literature Overview}

\section{Test Anxiety: Definition and Relevance in French Context}

When students experience anxiety in an assessment context considered threatening, they are facing test anxiety. Early studies defined test anxiety as a unidimensional attribute (e.g., Sarason, 1961). Test anxiety quickly became a multi-dimensional construct consisting in distinct but related components with cognitive and affective-physiological dimensions (Liebert \& Morris, 1967). Worry, which is the cognitive component, 
was based on negative thoughts, and emotionality, which is the affective-physiological component, was based on perception of physiological responses. Some researchers (e.g., Benson \& El-Zahhar, 1994) have separated these two components into two subscales. The two cognitive components focused on worry (thinking about failure) and test-irrelevant thinking (thinking about other things than evaluation). The two somatic components focused on tension (general autonomic arousal, e.g., feeling tense) and bodily symptoms (specific physiological effects, e.g., shaky hands).

Studying these different dimensions of test anxiety could be particularly relevant in the French educational context. Indeed, the OECD (2017) study presenting the PISA 2015 results on students' well-being highlighted that $62 \%$ of French students were afraid of struggling to pass an exam and $65 \%$ were afraid of receiving poor grades. Test anxiety is an undeniable reality for French students and assessing this phenomenon with a validated French scale may be the first step to develop research in this area, to understand this situation, and to overcome it. All the previous dimensions of test anxiety, primarily investigated in the English language, are considered performance-debilitating forms of anxiety experienced during tests (Putwain \& Symes, 2012). But the adaptive potential of anxiety has not been hitherto examined in test anxiety research.

\section{The Regulatory Dimension of Anxiety and Perceived Control}

In the educational domain, perceived control is defined as the degree of certainty of avoiding doing poorly and of achieving good grades (Martin, 2007). Empirical evidence has shown that a student with low perceived control anticipates failure and consequently has a greater likelihood of experiencing test anxiety (e.g., Pekrun, Goetz, Frentzel, Barchfeld, \& Perry, 2011). Recently, Putwain and Aveyard (2018) evidenced that perceived control was an antecedent of test anxiety and moderated the relationship between worry and examination performance. 
They also showed that students with higher perceived control performed better when their worry levels low and that this advantage diminished when worry increased. In sum, perceived control is considered a specific self-belief construct, related to the negative components of test anxiety, especially to the worry subscale. But it is not considered a fully-fledged component of test anxiety.

However, a regulatory dimension of anxiety was recently introduced into the conceptualization of performance anxiety in order to better understand the complex anxiety-performance relationships (Cheng et al., 2009). This dimension indicates an adaptive potential of anxiety (i.e., producing positive effects) which starts processes concerned with coping capacity following perceived threat (Cheng et al., 2009). It is represented by the construct of perceived control, which is related to the perception of feeling capable of coping and attaining goals under stress. In this three-dimensional model of performance anxiety, perceived control is not considered an antecedent of anxiety, but rather a fully-fledged dimension of anxiety (like cognitive anxiety and affective-physiological anxiety). The regulatory dimension of anxiety is not a coping strategy per se, but rather a reflection of potential coping capacity which is an integral part of anxiety (Cheng \& Hardy, 2016). From a theoretical perspective, a regulatory dimension is directly involved in the system of emotion in general and anxiety in particular (e.g., Ohman, 2000). Control is considered a key variable to better understand anxiety variations (Carver \& Scheier, 1988). Anxious individuals, in response to performance or examination pressure, probably evaluate environmental and internal threats, but also simultaneously their capacities to deal with the task (Cheng et al., 2009). Perceived control could also be directly viewed as an adaptive form of test anxiety with allocation of additional resources to the test or examination at hand. It may explain why some students perform well in tests and examinations despite their strong levels 
of cognitive and affective-physiological test anxiety. Consequently, including the regulatory dimension of anxiety as a positive component of test anxiety, and not as an antecedent, may be an interesting issue.

Furthermore, Attention Control Theory (Eysenck et al., 2007) has shown that high levels of stress and anxiety may indeed be detrimental for performance, but also lead individuals to invest more resources and more mental effort to maintain their performance despite stress and anxiety. Anxiety serves a motivational function and is not totally negative, maladaptive, or detrimental for performance (Nieuwenhuys \& Oudejans, 2012). From an evolutionary perspective, anxiety has a dual protective function: facilitating threat detection and mobilizing resources (Ohman, 2000). While the worry and emotionality dimensions of anxiety already include this protective function, a specific regulatory dimension of anxiety may be more adapted to explicitly represent this capacity (Cheng \& Hardy, 2016). But, when perceived control is independently assessed in the academic context, a specific scale is used, such as the four uncertain control items from the high-school version of the Motivation and Engagement Scale (Martin, 2007). Items are negatively-toned (e.g., “When I get a good mark I'm often not sure how I'm going to get that mark again”) and scores are reversed to indicate perceived control levels (e.g., Putwain \& Aveyard, 2018). In the three-dimensional model of performance anxiety, perceived control is positively-toned to directly reveal a sense of control rather than a lack of control (Cheng et al., 2009). It seems to be more appropriate to evidence a regulatory dimension of test anxiety considered positive among cognitive and negatively-toned affective-physiological components. But, for the moment, the regulatory dimension of anxiety, represented by perceived control, is not 
considered a positive component of test anxiety but rather an antecedent assessed with specific negatively-toned scales (Putwain \& Aveyard, 2018).

\section{Assessing the Test Anxiety Construct}

Several scales have been developed to assess test anxiety. The one most commonly used in the literature has been the Test Anxiety Inventory (Spielberger, 1980). Trait anxiety during tests or examinations was assessed through items related to worry and emotionality components. But two main discussion points have been highlighted for this scale (Zeidner, 2007): the low consistency of the worry subscale and the fact that the worry and emotionality dimensions substantially overlap. Secondly, the Cognitive Anxiety Scale (Cassady \& Johnson, 2002) focused on one of the two dimensions of test anxiety, namely the worry dimension. The authors showed that the worry dimension insufficiently represented all the cognitive processes associated with test anxiety, and that cognitive test anxiety had the strongest negative impact on academic performance measures. Despite its psychometric quality, this scale remains limited to the cognitive dimension of test anxiety and excludes its affective-physiological component. Thirdly, Hoferichter, Raufelder, Ringeisen, Rohrmann, and Bukowski (2016) recently validated the English version of the German Test Anxiety Questionnaire (Hodapp \& Benson, 1997), including four subscales: worry, emotionality, interferences (i.e., irrelevant thoughts that distract from the test at hand), and lack of confidence. Lack of confidence was correlated to test anxiety in previous studies (Mills, Pajares, \& Herron, 2006) and was included in this scale as a fully-fledged dimension of test anxiety. This approach seems relevant to assess the multifaceted nature of test anxiety, exploring new components of it. However, despite its interest, lack of confidence is another negative component of test anxiety, while positive components may also be envisaged, as seen above. Finally, Sarason (1984) validated the 
Reactions to Tests scale, followed by the RTA scale (Benson \& El-Zahhar, 1994). As seen previously, this scale assessed test anxiety through four components: worry and test-irrelevant thinking were the two cognitive components, and bodily symptoms and tension were the two somatic components. The RTA scale is a well-established instrument to assess test anxiety and is extensively used in this line of research (Putwain,

Woods, \& Symes, 2010b).

The vast majority of the previous scales were developed and validated in English. Some scales have been adapted into other languages. For example, the German Test Anxiety Inventory (Hodapp \& Benson, 1997) was developed from the English version of the Test Anxiety Inventory (Spielberger, 1980) and the validation of an Arabic version of Sarason's Reaction to Tests scale was conducted by Nasser, Takahashi, and Benson (1997). Often, these adaptations led to changes in the number and/or wording of items. For example, the scale of Nasser et al. (1997) includes a reduced set of 24 items as against the 40 items of Sarason's scale, in order to better respect the hypothesized four-factor structure of the original scale. But to date no validated French version of a test anxiety scale is available.

The RTA scale was selected in the present study because (1) it goes beyond the limitations identified in the previous scales, (2) it has been validated in numerous studies (e.g., Benson \& El-Zahhar, 1994; Hagtvet \& Benson, 1997, Putwain, Connors, \& Symes, 2010a, Putwain et al., 2010b), and (3) it measures through four components the non-adaptive dimension of anxiety. This non-adaptive dimension was mostly associated with a negative pattern of results when test anxiety was studied in relation with other variables such as achievement goals and perceptions of competence. In the literature on achievement goals, a positive relationship was found between performance-avoidance goals (i.e., not doing poorly relative to others) and test anxiety (e.g., Elliot \& McGregor, 1999), whereas performance-approach goals (i.e., doing well 
relative to others) and test anxiety relationships were weak or not significant (Elliot \& Church, 1997; Middleton \& Midgley, 1997; Sideridis, 2005). Mastery-avoidance goals (i.e., avoiding situations in which it is possible to fail or to regress) predicted a higher degree of test anxiety, but mastery-approach goals (i.e., developing competence and task mastery) did not (e.g., Elliot \& McGregor, 2001). Overall, avoidance-based goals were mostly linked with test anxiety. Using specifically the RTA scale, Putwain et al. (2010a) showed that worry and tension were related to mastery-avoidance goals, and bodily symptoms to performance-approach goals. Test anxiety has also been studied in relation with perceptions of competence. Generally, a low perceived competence predicted higher test anxiety (e.g., Zeidner \& Schleyer, 1999). The pattern was the same with the RTA scale and with specific measures of self-esteem in the school context: academic self-esteem was negatively related to worry, testirrelevant thinking, and tension (Putwain et al., 2010a).

\section{The Present Study}

The multidimensionality of test anxiety is well documented in the literature (Putwain et al., 2010b), research has been directed toward creating more precise measures of test anxiety (Benson \& El-Zahhar, 1994; Cassady \& Johnson, 2002; Hoferichter et al., 2016), and test anxiety has been related to numerous variables (e.g., achievement goals, perceptions of competence). But a French version of a test anxiety scale is lacking despite its strong interest in the French educational context. Moreover, the regulatory dimension of anxiety, represented by perceived control, has not been not included as a specific test anxiety component.

Consequently, the first purpose of the present study was to develop and validate a French version of the RTA scale (Benson \& El-Zahhar, 1994) so as to initiate a relevant line of inquiry in the French educational context. The second purpose of the study was to assess the factorial 
structure, the convergent validity, the discriminant validity, and the predictive validity of a five-factor version of the initial RTA scale augmented with perceived control. Comparison with three alternative models and measurement invariance across gender were also investigated. These two aims were conducted simultaneously.

\section{Method}

\section{Participants and Procedure}

The sample comprised 403 students (202 boys, 201 girls; $M_{\text {age }}=15.01$ years, $\left.S D=1.49\right)$ from two French collèges (ages 13-15) and two lycées (ages 15-18) in the south of France. As mentioned previously, the RTA scale (Benson \& El-Zahhar, 1994) does not exist in French. Consequently, a translation / back-translation procedure was carried out for the four subscales. Following the procedure of Brislin (1970), a professional translator translated the 20 items from English to French. A second translator translated the French version back into English. The two versions were then compared and reworked, leading to the final French version of the scale. The same procedure was applied to the six items of the subscale representing the regulatory dimension of anxiety (perceived control), which were extracted from the three-dimensional model of performance anxiety (Cheng et al., 2009). These items were then specifically adapted to test anxiety, replacing "performance" with "good grade", and were included in the initial RTA scale in order to create a five-factor version with 26 items: the French Revised Test Anxiety + Regulatory scale (FRTA+R). Following Gjersing, Caplehorn, and Clausen's (2010) procedure, a class of 25 French students filled in the translated questionnaire. They were asked to provide comments about potential problems of understanding with some items. After discussion between the 
researchers and the students, adjustments were made based on the subjective decision of the researchers involved in the study. Students of the pilot class were not included in the final sample of the study.

Afterwards, all the participants completed the final questionnaires in the classroom setting, on a day without examination or test, individually, and without communication between classmates. This study was approved by the Chief Education Officer of the Académie d'AixMarseille, by the schools' principals, and by the parents of students who had given their informed consent. The participants were assured of the anonymity of their responses, which would not affect their school careers.

\section{Measures}

Test anxiety. The FRTA+R scale previously created was used to measure test anxiety with five subscales: worry (e.g., "During tests I find myself thinking about the consequences of failing "), test-irrelevant thinking (e.g., "During tests I find myself thinking of things unrelated to the material being tested"), bodily symptoms (e.g., "I have difficulty breathing while taking a test”), tension (e.g., "During tests I feel very tense"), and perceived control (e.g., "During tests I believe in my ability to receive a good grade”). Students respond to the 26 items on a 4-point scale from almost never to almost always.

Achievement goals. Achievement goals were measured with the French Achievement Goals Questionnaire for Sport (Riou et al., 2012) adapted to test anxiety, replacing when necessary all the references to "sport" or "performance" with "test" and "grades". Using a 1 (strongly disagree) to 5 (strongly agree) scale, participants responded to the 12 items divided into four subscales: performance-approach goals (e.g., “During tests, my goal is to perform better than others"), mastery-approach goals (e.g., "During tests, I am striving to do my best”), 
performance-avoidance goals (e.g., "During tests, I am striving to avoid performing worse than others"), and mastery-avoidance goals (e.g.,

"During tests, my goal is to avoid making mistakes").

General school self-Esteem. General school self-esteem was measured with the specific subscale of the Self-Description Questionnaire II (Guérin, Marsh, \& Famose, 2003). Participants responded to the 10 items using a 1 (false) to 6 (true) scale (e.g., "Work in all school subjects is easy").

Table 1 shows descriptive statistics and internal consistencies of each scale, which were satisfactory for the three scales (Cronbach's $\alpha$ ranging from .70 to .93$)$.

\section{Please insert Table 1 about here}

\section{Data Analyses}

First, preliminary analyses were conducted to check and replace the missing values for the whole sample. Then, gross outliers were detected using the Mahalanobis distance at the multivariate level. If it was larger than the critical value of $\chi^{2}(9)=27.88, p<.001$, these participants were excluded. Finally, skewness and kurtosis statistics were used to verify the univariate normality of the distribution of test anxiety, achievement goals, and general school self-esteem scores for the whole sample. Skewness and kurtosis within \pm 2 indicated that the data followed a normal distribution.

Secondly, a Confirmatory Factor Analysis (CFA) was conducted on the covariance matrix of the FRTA+R items using the Lisrel 9.1 program, and the solution was generated using maximum likelihood estimation. The root mean square error of approximation (RMSEA), the 
incremental fit index (IFI), the comparative fit index (CFI), and the standardized root mean square residual (SRMR) were used as fit indices in our study. Following Byrne (2010), CFI $\geq .95 ;$ IFI $\geq .95$ and RMSEA $\leq .05$ were the criteria for a good fitting model, and CFI $\geq .90 ;$ IFI $\geq .90$ and RMSEA $\leq .08$ were the criteria for an acceptable fitting model. The stability in other samples was represented by the $90 \%$ confidence interval of the RMSEA. A good fit for SRMR was based on a value less than .08 (Hu \& Bentler, 1999). Cronbach's $\alpha$ were calculated to confirm internal consistency of the five subscales of the FRTA+R scale. They are considered satisfactory above .70 (Nunnally \& Bernstein, 1994).

McDonald's omega was also used to estimate internal consistency to limit the possibility of under- or over-estimating reliability, with a cut-off value of .70 (Sijtsma, 2009).

Thirdly, convergent validity of the FRTA+R scale was explored through three procedures (Hair, Black, Babin, Anderson, \& Tatham, 2006). The first procedure is based on the item reliability, which is significant if the factor loading of each item is higher than .50. The second procedure focuses on composite reliability, which is a measure of the overall reliability of heterogeneous but similar items loaded on a latent factor. Values greater than .70 are recommended. But if other indicators on the construct's validity are good, values are also acceptable from .60 to .70 . The third procedure is based on the average variance extracted (AVE), which measures the amount of variance captured by a construct versus the amount due to measurement error. It needs to be higher than .50 of the total variance but .40 is also acceptable if composite reliability is higher than .60 . 
Fourthly, discriminant validity analyses were conducted to assess the extent to which the constructs differ. The diagonal elements of a latent correlation matrix are replaced by $\sqrt{\mathrm{AVE}}$. The items are considered independent of one another if $\sqrt{\mathrm{AVE}}$ for each factor is higher than the correlations between this factor and other factors (Teo, Lee, Chai, \& Wong, 2009).

Fifthly, the fit of the five-factor baseline model was compared with three alternative models. The model with the smallest Expected Cross-Validation Index (ECVI) showed the greatest fit to the data (Byrne, 2010).

Sixthly, gender invariance of the scale was tested following the procedure of Putnick and Bornstein based on configural, metric and scalar levels (2016). A maximum change of -.01 in CFI and a change of .015 in RMSEA were the criterion to validate a level (Chen, 2007). The JASP software (version 0.10) was used to test measurement invariance across gender.

Finally, the predictive validity of the RTA+R scale was assessed using hierarchical regression analyses. Gender and age were entered in Step 1 to control these variables, which may influence the observed variance in test anxiety scores (Zeidner, 2007). The four achievement goals and general school self-esteem were entered in Step 2 to study how these two variables predicted the five components of test anxiety. Because multiple tests were performed, the Holm-Bonferroni correction was used to judge significance (Holm, 1979; Gaetano, 2013). These analyses were conducted with Statistica 12 for PC. 


\section{Results}

\section{Preliminary Results}

Missing values were replaced by the scale mean because less than $0.2 \%$ of the sample data were missing. Only two participants showed a Mahalanobis distance at the multivariate level larger than the critical value. They were excluded from the present study as multivariate outliers. Skewness and kurtosis statistics showed that test anxiety, achievement goals, and general school self-esteem were normally distributed.

\section{Factorial Structure, Convergent Validity, and Discriminant Validity}

The results of the first CFA supported the hypothesized five-factor structure of the FRTA+R scale. Following Byrne's (2010) recommendations, the fit statistics met the criteria for an acceptable fitting model $\left(\chi^{2}(289, N=401)=695.61, p<.001, \mathrm{CFI}=.95, \mathrm{IFI}=.95\right.$, $\mathrm{SRMR}=.08, \mathrm{RMSEA}=.059,90 \% \mathrm{CI}=.054-.065)$. A satisfactory level of internal consistency was observed for the five subscales $(\mathrm{Cronbach}$ 's $\alpha$ ranging from .71 to .83). But the first procedure of convergent validity analyses was not satisfactory, with 8 out of 26 items (30.8\%) obtaining a loading lower than .50. Consequently, these items were removed from the initial scale, similarly to the procedure of Nasser et al. (1997) when they validated an Arabic version of the Reaction to Tests scale initially validated in English. Skewness and kurtosis were again calculated.

Results were also satisfactory for the new version of the scale (see Table 1). A second CFA was conducted on the 18 remaining items (see Table 2, which presents the selected items of the final FRTA+R scale). The results of the CFA were significantly improved. The fit statistics now met the criteria for a good fitting model $\left(\chi^{2}(125, N=401)=245.54, p<.001, \mathrm{CFI}=.98, \mathrm{IFI}=.98, \mathrm{SRMR}=.05, \mathrm{RMSEA}=.049,90 \% \mathrm{CI}=.040-\right.$ 058). Based on Cronbach's alpha and McDonald's omega, a satisfactory level of internal consistency was also observed for the worry, test- 
irrelevant thinking, bodily symptoms, tension, and perceived control subscales, albeit somewhat weak for the worry factor concerning the McDonald's omega result (see Table 1). It is interesting to note that, as expected, the new positive component of test anxiety (perceived control) was found to be negatively related with the four negative components of test anxiety.

The standardized factor loadings ranged from .54 to .91 , which validated the first procedure of the convergent validity analyses. Composite reliability was satisfactory for four of the five factors of the FRTA+R scale (ranging from .73 to .87) and was slightly smaller for the worry dimension (.67). Finally, as seen in Table 1, AVE was acceptable for the five factors of the scale according to the recommendations of Hair et al. (2006). Consequently, convergent validity of the FRTA+R scale was validated.

Discriminant validity was assessed to show if each factor shares more variance with its items than it does with other factors. Following the recommendations of Teo et al. (2009), discriminant validity was found satisfactory for all the factors of the FRTA+R scale (see Table 1). The standardized factor loadings and measurement error for the selected items are presented in Table 2.

\section{Please insert Table 2 about here}

\section{Comparison with Alternative Models}

The five-factor baseline model was compared with three alternative models: (1) a three-factor model in which worry and test-irrelevant thinking load on a combined latent factor (cognitive dimension of test anxiety), bodily symptoms and tension load on a combined latent factor (affective-physiological dimension of test anxiety), and perceived control loads on its hypothesized latent factor; (2) a two-factor model in which, test-irrelevant thinking, bodily symptoms, and tension load on a combined latent factor (negative dimension of test anxiety) and perceived control 
loads on its hypothesized latent factor (positive dimension of test anxiety); and (3) a one-factor model whereby worry, test-irrelevant thinking, bodily symptoms, tension and perceived control load on a combined latent factor (general test anxiety). The results presented in Table 3 clearly indicated that the five-factor baseline model had a better fit to the data than the three alternative models.

\section{Please insert Table 3 about here}

\section{Gender Invariance}

The FRTA $+\mathrm{R}$ scale was invariant across gender at the configural $(\Delta \mathrm{CFI}=-.006, \Delta \mathrm{RMSEA}=.004)$, metric $(\Delta \mathrm{CFI}=-.004, \Delta \mathrm{RMSEA}=$ $.000)$ and scalar $(\Delta \mathrm{CFI}=-.003, \Delta \mathrm{RMSEA}=.001)$ levels.

\section{Predictive Validity}

Five consecutive hierarchical regression analyses were conducted to investigate how achievement goals and general school self-esteem predicted the five components of test anxiety, controlling for gender (male $=1$, female $=-1$ ) and age. General school self-esteem was found to be a negative predictor of worry, test-irrelevant thinking, bodily symptoms, and tension, and a positive predictor of perceived control. The results also showed that worry was negatively predicted by gender and positively by mastery-avoidance goals. Test-irrelevant thinking was negatively predicted by mastery-based goals and positively by performance-avoidance goals. Bodily symptoms were positively predicted by masteryavoidance goals. Tension was negatively predicted by gender and positively predicted by avoidance-based goals. Finally, perceived control was positively predicted by gender and mastery-approach goals. After the Holm-Bonferroni correction (Holm, 1979; Gaetano, 2013), all these results remained statistically significant, except for gender which negatively predicted worry, for performance-avoidance goals which positively 
predicted test-irrelevant thinking, and for general school self-esteem which negatively predicted bodily symptoms. Table 4 presents the detailed results.

\section{Please insert Table 4 about here}

\section{Discussion}

In the present study, we examined the validity of the French version of the $R T A+R$ scale, which added to the existing English version of the RTA scale (Benson \& El-Zahhar, 1994) the regulatory dimension of anxiety represented by perceived control (Cheng et al., 2009), in order to reflect the potential adaptive capacity underlying the dynamics of anxiety.

While the initial RTA scale has demonstrated good psychometric properties in numerous studies (e.g., Benson \& El-Zahhar, 1994; Hagtvet \& Benson, 1997), the French version of the scale and the addition of a fifth dimension (perceived control), initially not measured by the RTA scale, have led to a five-factor model (FRTA+R scale) also with good psychometric properties. Although the results of the first CFA conducted on the 26 items were acceptable following the recommendations of Byrne (2010), some items from the original RTA scale have been deleted in the French version due to their low factor loadings, in order to improve the convergent validity and the discriminant validity of the final scale. According to Nasser et al. (1997), the first aim of this procedure of item deletion is to better respect the hypothesized factorial structure of the initial scale. Consequently, the five-factor structure of the 18-item FRTA+R scale received good support for fitting the data. In the literature, test anxiety is not a unidimensional attribute, but rather a multi-dimensional construct including cognitive and affectivephysiological components. The multidimensionality of test anxiety may now be considered with a third component reflecting the adaptive 
potential of test anxiety. However, perceived control is also considered in the literature more as an antecedent of academic anxiety than a component (Martin \& Marsh, 2008; Martin et al., 2010) or as a moderator between test anxiety and examination performance (Putwain \& Aveyard, 2018). According to the definition of Martin (2010), perceived control is a self-concept that affects how students prepare for and perform in tests and examinations. When perceived control is high, students identify the relations between their effort, their strategy and the academic outcome, and when perceived control is low, helplessness or self-sabotage may occur more frequently (Martin, 2002). By contrast, in the FRTA+R scale, the regulatory dimension of anxiety represented by perceived control is not a distinct coping effort, a self-concept, preparatory step, or strategy, but rather a kind of potential coping capacity directly involved in the anxiety dynamics (e.g., Cheng et al., 2009; Ohman, 2000). This regulatory dimension of anxiety leads a student to mobilize mental and/or physical resources to tackle the threats in the dynamics of the anxiety response experienced during tests or examinations.

Perceived control is one of the key factors to maintain a certain performance level or even to increase it even if the negative components of anxiety are high (Cheng \& Hardy, 2016). Using the FRTA+R scale, it would then be conceivable to highlight students who succeed at school with both high levels of cognitive and/or affective-physiological test anxiety and high levels of perceived control. It is also possible that other kinds of profiles may be found. For example, higher test anxiety may be characterized by high cognitive test anxiety, high physiological test anxiety, and low perceived control, and may lead this kind of students to catastrophic performances during tests or examinations. Consequently, and to take it a step further, integrating the measure of objective performance (e.g., examination grades) and using a cluster analysis may be useful to place students into relatively homogenous groups according to their test anxiety scores in the three components (cognitive, somatic, 
perceived control). This will allow researchers to examine whether students' examination performance differs depending on the cluster to which they belong. While studies focusing on test anxiety have usually used cross-sectional and longitudinal designs, cluster analysis has shown promising prospects for examining different combinations of test anxiety components. This method has already been used with test anxiety in relation with academic buoyancy and examination performance (Putwain \& Daly, 2013), using a person-centered approach rather than a more classical variable-centered approach in the test anxiety literature.

The results of the hierarchical regression analyses were mostly consistent with the literature and showed the predictive validity of the FRTA+R scale. In a first step, the results concerning the four negative dimensions of test anxiety are discussed. Reproducing the results of previous studies (e.g., Elliot \& McGregor, 1999; Putwain \& Symes, 2012), avoidance-based goals were found to be positive predictors of different negative components of test anxiety. Performance-avoidance goals positively predicted tension, and mastery-avoidance goals positively predicted worry, bodily symptoms, and tension. Avoidance-based goals are more likely to induce test anxiety due to anticipation of failure and low perceived controllability frequently associated with these two kinds of goals (Putwain \& Symes, 2012). Mastery-avoidance goals were found in the present study as stronger predictors of the negative components of test anxiety than performance-avoidance goals, perhaps due to the selfreferenced nature of the mastery-avoidance goals. This result was also found in other studies (e.g., Putwain et al., 2010b). Surprisingly, masteryavoidance goals were negative predictors of test-irrelevant thinking. This result suggests that focusing on not doing poorly relative to task demands or own's performance trajectory still leads participants to concentrate on the task during the test or the examination, and consequently restricts test-irrelevant thinking. This assumption is consistent with the fact that mastery-approach goals have also been found here as negative 
predictors of test-irrelevant thinking. Furthermore, the literature has identified an unequivocal pattern of results with inverse relations between test anxiety and academic self-esteem (e.g., Putwain et al., 2010b), which was also identified in the present study for three of the four negative factors (worry, test-irrelevant thinking, tension). Negative self-beliefs were often related to maladaptive outcomes, such as test anxiety. All these results concerning the four negative components of test anxiety contribute to confirming the predictive validity of the French version of the scale.

In a second step, the specific results concerning perceived control are discussed. While mastery-approach goals are unrelated to the negative components of test anxiety in the test anxiety literature (we have found the same pattern in our study, except for test-irrelevant thinking), mastery-approach goals were interestingly highlighted here as significant positive predictors of perceived control. Mastery-approach goals are considered the most adaptive goals in the literature on achievement goals in the educational context (e.g., Elliot \& McGregor, 2001; Van Yperen, Blaga, \& Postmes, 2014) and perceived control indicates an adaptive potential of anxiety (Cheng et al., 2009). This result reinforces the integration of perceived control as a positive dimension of test anxiety. Moreover, this new dimension was positively and strongly predicted by general school self-esteem. Perceived control envisaged as a regulatory dimension of anxiety has previously been studied in relation with several performance-related variables containing both adaptive and maladaptive features. For example, Cheng and Hardy (2016) showed that perceived control was predicted by positive dimensions of perfectionism and self-talk (but not by their negative ones) and predicted approach coping (but not avoidance coping). In sum, the adaptive potential of the regulatory dimension of anxiety was confirmed because perceived control was related to adaptive dimensions of the tested variables and not with their maladaptive dimensions. In the present study, perceived control followed the same pattern and was predicted by both adaptive dimensions of achievement goals (approach-based goals) and high 
academic self-esteem, while cognitive and affective-physiological dimensions of test anxiety were predicted by negative dimensions of these variables (avoidance-based goals and low academic self-esteem).

Our results also showed that tension was higher for girls compared with boys, whereas it was the opposite for perceived control. No significant results were found for the predicting role of age. In the literature, age and gender were significant predictors of test anxiety in terms of its negative dimensions, but only a small proportion of variance was predicted (Putwain, 2007; Whitaker Sena, Lowe, \& Lee, 2007). Test anxiety was higher for girls than for boys and the emotionality component of test anxiety was more influenced by gender differences than the worry component (e.g., Putwain, 2007; Zeidner \& Schleyer, 1999), which was confirmed in our study. This observation may be reinforced by the fact that perceived control is inversely higher for boys compared with girls. While no significant gender differences were evidenced in the sport domain for this positive component of performance anxiety (Cheng \& Hardy, 2011), the pattern is different with test anxiety. Some speculative explanations exist, such as different socialization practices between girls and boys (Putwain et al., 2010a), but further studies are necessary to better understand why boys have a higher perceived control than girls when anxiety is induced by a test or an examination.

Our study is not without limitations. The first is that perceived control as a positive component of test anxiety was only validated in French. English validation of this component added to the original RTA scale may be relevant to throw more light on some variables previously related to test anxiety through its cognitive and affective-physiological components. It may also be instructive to examine the generalizability of our results with cross-cultural designs, standardized tests, and measures adapted to younger students, because test anxiety in children is different than in adolescents and adults due to developmental differences (Wren \& Benson, 2004). The second limitation is that a test-retest procedure was 
not conducted, and our research was based on a single-session survey methodology, with the test anxiety data collected retrospectively. But retrospective studies have advantages, for example reducing effects of response bias due to social desirability or reducing ethical concerns when test anxiety is assessed during an examination, which can disrupt it. Prospective and longitudinal designs may be used to complete this initial work. Finally, we linked the five factors of test anxiety with the 2 × 2 model of achievement goals and general school self-esteem, which are some key variables in the test anxiety literature. Many other variables may be examined, such as examination performance or implicit theories of intelligence (Dweck \& Molden, 2005).

\section{Conclusions}

While test anxiety can be mostly considered a performance-debilitating form of anxiety (Putwain \& Symes, 2012), the introduction of the regulatory dimension of anxiety (represented by perceived control) in the initial RTA scale could now help to accurately examine the adaptive potential of test anxiety and to better understand and explain academic performance. While French students are particularly anxious during tests and examinations (OECD, 2017), continuing and developing this work using the FRTA+R scale would allow greater understanding of test anxiety in the French educational context and would allow potential improvement of the situation. In cross-cultural perspectives, introducing perceived control as an integral part of test anxiety may be envisaged in studies using the original English RTA scale based on the cognitive and affective-physiological components. Further research is needed to study the explanatory and predictive power of this modified scale because the establishment of construct validity is an on-going process (Smith \& McCarthy, 1995). 


\section{Compliance with Ethical Standards}

\section{Conflict of Interest}

On behalf of all authors, the corresponding author states that there is no conflict of interest.

\section{Research Involving Human Participants and/or Animals}

All procedures performed in studies involving human participants were in accordance with the ethical standards of the institutional and/or national research committee and with the 1964 Helsinki declaration and its later amendments or comparable ethical standards. This article does not contain any studies with animals performed by any of the authors.

\section{Informed Consent}

Informed consent was obtained from all individual participants included in the study. 


\section{References}

Benson, J., \& El-Zahhar, N. (1994). Further refinement and validation of the Revised Test Anxiety Scale with cross-validation. Structural

Equation Modelling, 1(3), 203-221.

Blunch, N. (2008). Introduction to structural equation modelling using SPSS and AMOS. London: Sage.

Brislin, R. W. (1970). Back translation for cross-cultural research. Journal of Cross-Cultural Psychology, 1(3), $185-216$.

Byrne, B. M. (2010). Structural equation modelling with AMOS: Basic concepts, applications and programming. New York, NY: Routledge.

Carver, C. S., \& Scheier, M. F. (1988). A control-process perspective on anxiety. Anxiety Research, 1(1), 17-22.

Cassady, J. C., \& Johnson, R. E. (2002). Cognitive test anxiety and academic performance. Contemporary Educational Psychology, 27(2), 270295.

Chen, F. F. (2007). Sensitivity of goodness of fit indexes to lack of measurement invariance. Structural Equation Modeling 14(3), 464-504.

Cheng, W. N. K., \& Hardy, L. (2016). Three-dimensional model of performance anxiety: Tests of the adaptive potential of the regulatory dimension of anxiety. Psychology of Sport and Exercise, 22, 255-263.

Cheng, W. N. K., Hardy, L., \& Markland, D. (2009). Toward a three-dimensional conceptualization of performance anxiety: Rationale and initial measurement development. Psychology of Sport and Exercise, 10(2), 271-278.

Cury, F., Da Fonseca, D., Zahn, I., \& Elliot, A. (2008). Implicit theories and IQ test performance: A sequential mediational analysis. Journal of Experimental Social Psychology, 44(3), 783-791.

Dweck, C. S., \& Molden, D. C. (2005). Self-Theories: Their impact on competence motivation and acquisition. In A. J. Elliot, \& C. S. Dweck (Eds.), Handbook of competence and motivation (pp. 122-140). New York: Guilford Press.

Elliot, A. J., \& Church, M. A. (1997). A hierarchical model of approach and avoidance achievement motivation. Journal of Personality and Social Psychology, 72(1), 218-232. 
Elliot, A. J., \& McGregor, H. A. (1999). Test anxiety and the hierarchical model of approach and avoidance achievement motivation. Journal of Personality and Social Psychology, 76(4), 628-644.

Elliot, A. J., \& McGregor, H. A. (2001). A 2 X 2 achievement goal framework. Journal of Personality and Social Psychology, 80(3), 501-519.

Eysenck, M. W., Derakshan, N., Santos, R., \& Calvo, M. G. (2007). Anxiety and cognitive performance: Attentional control theory. Emotion, $7(2), 336-353$.

Gaetano, J. (2013). Holm-Bonferroni sequential correction: An EXCEL calculator. Retrieved from http://www.researchgate.net/ publication/242331583_Holm-Bonferroni_Sequential_Correction_An_EXCEL_Calculator-Ver.1.2

Gjersing, L., Caplehorn, J., \& Clausen, T. (2010). Cross-cultural adaptation of research instruments: Language, setting, time and statistical considerations. BMC Medical Research Methodology, 10(13), n.p.

Guérin, F., Marsh, H. W., \& Famose, J. P. (2003). Construct validation of the Self-Description Questionnaire II with a French sample. European Journal of Psychological Assessment, 19(2), 142-150.

Hagtvet, K. A., \& Benson, J. (1997). The motive to avoid failure and test anxiety responses: Empirical support for integration of two research traditions. Anxiety, Stress, and Coping, 10(1), 35-57.

Hair, J. F., Jr., Black, W. C., Babin, B. J., Anderson, R. E., \& Tatham, R. L. (2006). Multivariate data analysis (6th ed.). New Jersey: PrenticeHall International.

Hodapp, V., \& Benson, J. (1997). The multidimensionality of test anxiety: A test of different models. Anxiety, Stress, and Coping, 10(3), 219244.

Hoferichter, F., Raufelder, D., Ringeisen, T., Rohrmann, S., \& Bukowski, W. M. (2016). Assessing the multi-faceted nature of test anxiety among secondary school students: An English version of the German Test Anxiety Questionnaire: PAF-E. The Journal of Psychology, 150(4), 450-468.

Holm, S. (1979). A simple sequentially rejective multiple test procedure. Scandinavian Journal of Statistics, 6(2), 65-70. 
Hu, L. T., \& Bentler, P. M. (1999). Cutoff criteria for fit indexes in covariance structure analysis: Conventional criteria versus new alternatives. Structural Equation Modeling: A Multidisciplinary Journal, 6(1), 1-55.

Liebert, R. M., \& Morris, L. W. (1967). Cognitive and emotional components of test anxiety: A distinction and some initial data. Psychological Reports, 20(3), 975-978.

Martin, A. J. (2002). Motivation and academic resilience: Developing a model for student enhancement. Australian Journal of Education, 46(1), $34-49$.

Martin, A. J. (2007). Examining a multi-dimensional model of student motivation and engagement using a construct validation approach. British Journal of Educational Psychology, 77(2), 412-440.

Martin, A. J. (2010). Building classroom success: Eliminating academic fear and failure. London: Continuum.

Martin, A. J., Colmar, S. H., Davey, L. A., \& Marsh, H. W. (2010). Longitudinal modelling of academic buoyancy and motivation: Do the '5Cs' hold up over time? British Journal of Educational Psychology, 80(3), 473-496.

Martin, A. J., \& Marsh, H. W. (2008). Academic buoyancy: Towards an understanding of students' everyday academic resilience. Journal of School Psychology, 46(1), 53-83.

Middleton, M., \& Midgley, C. (1997). Avoiding the demonstration of lack of ability: An under explored aspect of goal theory. Journal of Educational Psychology, 89(4), 710-718.

Mills, N., Pajares, F., \& Herron, C. (2006). A reevaluation of the role of anxiety: self-efficacy, anxiety, and their relation to reading and listening proficiency. Foreign Language Annals, 39(2), 276-295.

Nasser, F., Takahashi, T., \& Benson, J. (1997). The structure of test anxiety in Israeli-Arab high school students: An application of confirmatory factor analysis with miniscales. Anxiety, Stress, and Coping, 10(2), 129-151.

Nieuwenhuys, A., \& Oudejans, R. R. (2012). Anxiety and perceptual-motor performance: toward an integrated model of concepts, mechanisms, and processes. Psychological Research, 76(6), 747-759.

Nunnally, J. C., \& Bernstein, I. H. (1994). Psychometric theory (3rd ed.). New York: McGraw-Hill. 
OECD (2017). PISA 2015 Results (Volume III): Students' Well-Being. Paris Publishing: OECD.

Ohman, A. (2000). Fear and anxiety: evolutionary, cognitive, and clinical perspectives. In M. Lewis, \& J. M. Haviland-Jones (Eds.), Handbook of emotions (2nd ed., pp. 573-593). New York: Guilford Press.

Pekrun, R., Goetz, T., Frenzel, A. C., Barchfeld, P., \& Perry, R. P. (2011). Measuring emotions in students' learning and performance: The achievement emotions questionnaire (AEQ). Contemporary Educational Psychology, 36(1), 36-48.

Putnick, D. L., \& Bornstein, M. H. (2016). Measurement invariance conventions and reporting: The state of the art and future directions for psychological research. Developmental Review, 41, 71-90.

Putwain, D. W. (2007). Test anxiety in UK schoolchildren: Prevalence and demographic patterns. British Journal of Educational Psychology, 77(3), 579-593.

Putwain, D. W., \& Aveyard, B. (2018). Is Perceived Control a Critical Factor in Understanding the Negative Relationship Between Cognitive Test Anxiety and Examination Performance? School Psychology Quarterly, 33(1), 65-74.

Putwain, D. W., Connors, L., \& Symes, W. (2010a). Do cognitive distortions mediate the test anxiety-examination performance relationship? Educational Psychology, 30(1), 11-26.

Putwain, D. W., \& Daly, A. L. (2013). Do clusters of test anxiety and academic buoyancy differentially predict academic performance? Learning and Individual Differences, 27, 157-162.

Putwain, D. W., \& Symes, W. (2012). Achievement goals as mediators of the relationship between competence beliefs and test anxiety. British Journal of Educational Psychology, 82(2), 207-224.

Putwain, D. W., Woods, K. A., \& Symes, W. (2010b). Personal and situational predictors of test anxiety of students in post-compulsory education. British Journal of Educational Psychology, 80(1), 137-160.

Riou, F., Boiché, J., Doron, J., Romain, A. J., Corrion, K., Ninot, G., d'Arripe-Longueville, F., \& Gernigon, C. (2012). Development and validation of the French achievement goals questionnaire for sport and exercise (FAGQSE). European Journal of Psychological Assessment, 28(4), 313-320. 
Rost, D. H., \& Schermer, F. J. (1992). Stabilization of test anxiety. In K. A. Hagtvet, \& T. B. Johnsen (Eds.), Advances in test anxiety research,

Vol. 7 (pp. 84-102). Lisse, the Netherlands: Swets and Zeitlinger.

Sarason, I. G. (1961). Test anxiety and the intellectual performance of college students. Journal of Educational Psychology, 52(4), 201-206.

Sarason, I. G. (1984). Stress, anxiety and cognitive interference: reactions to tests. Journal of Personality and Social Psychology, 46(4), 929-938.

Sideridis, G. D. (2005). Classroom goal structures and hopelessness as predictors of day-to-day experience at school: Differences between students with and without learning disabilities. International Journal of Educational Research, 43(4-5), 308-328.

Sijtsma, K. (2009). On the use, the misuse, and the very limited usefulness of Cronbach's alpha. Psychometrika, 74(1), 107.

Smith, G. T., \& McCarthy, D. M. (1995). Methodological considerations in the refinement of clinical assessment instruments. Psychological Assessment, 7(3), 300-308.

Spielberger, C. D. (1980). Preliminary professional manual for the test anxiety inventory. Palo Alto, CA: Consulting Psychologists Press.

Teo, T., Lee, C. B., Chai, C. S., \& Wong, S. L. (2009). Assessing the intention to use technology among pre-service teachers in Singapore and Malaysia: A multigroup invariance analysis of the Technology Acceptance Model (TAM). Computers and Education, 53(3), $1000-1009$.

Van Yperen, N. W., Blaga, M., \& Postmes, T. (2014). A meta-analysis of self-reported achievement goals and nonself-report performance across three achievement domains (work, sports, and education). PloS One, 9(4), e93594.

Whitaker Sena, J. D., Lowe, P A., \& Lee, S. W. (2007). Significant predictors of test anxiety among students with and without learning disabilities. Journal of Learning Disabilities, 40(4), 360-376.

Wren D. G., \& Benson J. (2004). Measuring test anxiety in children: scale development and internal construct validation. Anxiety, Stress, and Coping, 17(3), 227-240.

Zeidner, M. (2007). Test anxiety in educational contexts. In P. A. Schutz \& R. Pekrun (Eds.), Emotion in education (pp. 165-184). Burlington, MA: Elsevier.

Zeidner, M., \& Schleyer, E. J. (1999). Test anxiety in intellectually gifted students. Anxiety, Stress, and Coping, 12(2), 163-189. 
Table 1

Descriptive statistics, correlations, internal consistencies, univariate normality, composite reliability, average variance extracted, and discriminant validity for the final version of the $F R T A+R$ scale

\begin{tabular}{|c|c|c|c|c|c|c|c|c|c|c|c|c|}
\hline Variable & 1 & 2 & 3 & 4 & 5 & Pap & Map & Pav & Mav & GSSE & Age & Gender \\
\hline 1. Worry & $(.64)$ & & & & & -.02 & -.03 & $.14 * *$ & $.21 * * *$ & $-.23 * * *$ & .07 & $-.15 * *$ \\
\hline 2. Test-irrelevant thinking & .07 & $(.84)$ & & & & $-.11 *$ & $-.26 * * *$ & .04 & $-.17 * * *$ & $-.21 * * *$ & .00 & -.01 \\
\hline 3. Bodily symptoms & $.46^{* * *}$ & .03 & $(.69)$ & & & $-.14 * *$ & -.06 & .08 & $.23 * * *$ & $-.21 * * *$ & .01 & $-.12 *$ \\
\hline 4. Tension & $.62 * * *$ & -.04 & $.52 * * *$ & $(.75)$ & & -.06 & -.01 & $.20 * * *$ & $.27 * * *$ & $-.23 * * *$ & .01 & $-.19 * * *$ \\
\hline 5. Perceived control & $-.29 * * *$ & $-.16^{* *}$ & $-.26 * * *$ & $-.27 * * *$ & $(.74)$ & $.22 * * *$ & $.33 * * *$ & -.07 & -.07 & $.61 * * *$ & $-.13 * *$ & $.19 * * *$ \\
\hline Mean & 2.33 & 2.30 & 1.51 & 2.51 & 2.48 & 2.61 & 4.05 & 3.27 & 3.69 & 4.11 & 15.06 & - \\
\hline Standard deviation & 0.77 & 0.94 & 0.67 & 0.84 & 0.65 & 1.36 & 0.97 & 1.27 & 1.00 & 1.04 & 1.49 & - \\
\hline Cronbach's $\alpha$ & .70 & .87 & .71 & .83 & .85 & .93 & .88 & .84 & .81 & .90 & - & - \\
\hline McDonald's omega & .68 & .87 & .73 & .83 & .86 & - & - & - & - & - & - & - \\
\hline Skewness & .16 & .27 & 1.43 & -.01 & .22 & .34 & -1.10 & -.36 & -.73 & -.59 & - & - \\
\hline Kurtosis & -.77 & -.98 & 1.37 & -1.01 & -.13 & -1.17 & .68 & -.98 & .10 & -.25 & - & - \\
\hline Composite reliability & .67 & .87 & .73 & .84 & .86 & - & - & - & - & - & - & - \\
\hline AVE & .41 & .70 & .48 & .56 & .54 & - & - & - & - & - & - & - \\
\hline
\end{tabular}

Notes. ${ }^{*} p<.05 .{ }^{* *} p<.01 .{ }^{* * *} p<.001$. Pap = Performance-approach goals, Map = Mastery-approach goals, Pav = Performance-avoidance goals, Mav = Mastery-avoidance goals, GSSE = General school self-esteem, AVE = Average Variance Extracted, the diagonal elements in bold represent

$\sqrt{\mathrm{AVE}}$

for

the

$\mathrm{RTA}+\mathrm{R}$

questionnaire. 
Table 2

Standardized factor loadings and measurement error for the selected items (French and English version).

Factors/Items

Factor 1: Worry

* Thinking about my grade in a course interferes with my work on tests

(Lors des évaluations, penser à la note que je pourrais avoir perturbe mon travail)

* I seem to defeat myself while taking important tests

(J'ai l'impression de me décomposer quand je passe des évaluations importantes)

* During tests I find myself thinking about the consequences of failing

(Lors des évaluations, je pense souvent aux conséquences de l'échec)

Factor 2: Test-irrelevant thinking

* During tests I find myself thinking of things unrelated to the material being tested

(Lors des évaluations, je pense souvent à des choses qui n'ont rien à voir avec ce que je dois faire)

* I think about current events during a test

(Lors des évaluations, je pense souvent à d'autres choses)

* During tests I find I am distracted by thoughts of upcoming events

(Lors des évaluations, je suis déconcentré(e) en pensant à d'autres événements à venir)

Factor 3: Bodily symptoms

* I sometimes find myself trembling before or during tests

(Je tremble parfois avant ou pendant les évaluations)

* While taking a test my muscles are very tight

(Durant les évaluations, mes muscles sont très tendus)

* I have difficulty breathing while taking a test

(Durant les évaluations, j'ai du mal à respirer)

\section{Factor 4: Tension}

* During tests I feel very tense

(Lors des évaluations, je me sens très tendu(e))

* I worry a great deal before taking an important exam

(Je m'inquiète beaucoup avant de passer des évaluations importantes)

* I am anxious about tests

(Les évaluations me rendent anxieux / anxieuse)

* I worry before the test because I do not know what to expect

(Je m'inquiète beaucoup avant les évaluations car je ne sais pas à quoi m'attendre)

Factor 5: Perceived control

* During tests I believe in my ability to receive a good grade

(Lors des évaluations, je me sens capable d'avoir une bonne note)

* During tests I feel ready to receive a good grade

(Lors des évaluations, je me sens prêt(e) à avoir une bonne note)

* During tests I believe that I have the resources to receive a good grade

(Lors des évaluations, je crois que j'ai les ressources pour avoir une bonne note)

* During tests I believe I can receive a good grade

(Lors des évaluations, je crois que je peux avoir une bonne note)

* During tests I feel confident about my upcoming grade

(Lors des évaluations, je suis confiant dans la note que je pourrais avoir) 
Table 3

Results of the confirmatory factor analyses for the five-factor model (baseline model) and for three alternative models.

\begin{tabular}{llllllllll}
\hline$\chi^{2}$ & $d f$ & $p$ & RMSEA & $90 \%$ & CI RMSEA & CFI & IFI & SRMR & ECVI
\end{tabular}

\begin{tabular}{ccccccccrrr}
\hline Five-factor model & 245.54 & 125 & $<.001$ & .049 & $.040-.058$ & .98 & .98 & .05 & 0.842 \\
Three-factor model & 1044.04 & 132 & $<.001$ & .131 & $.124-.139$ & .83 & .83 & .11 & 2.798 \\
Two-factor model & 1058.89 & 134 & $<.001$ & .131 & $.124-.139$ & .83 & .83 & .11 \\
One factor model & 1719.14 & 135 & $<.001$ & .171 & $.164-.178$ & .71 & .71 & .15 & 4.467
\end{tabular}

Notes. RMSEA = Root Mean Square Error of Approximation, CI = Confidence Interval, CFI = Comparative Fit Index, IFI = Incremental Fit Index, SRMR = Standardized Root Mean-square Residual, ECVI = Expected Cross-Validation Index 
Table 4

Summary of hierarchical regression analyses predicting test anxiety components

\begin{tabular}{|c|c|c|c|c|c|c|c|c|c|c|}
\hline & \multicolumn{2}{|c|}{ Worry } & \multicolumn{2}{|c|}{$\begin{array}{l}\text { Test-irrelevant } \\
\text { thinking }\end{array}$} & \multicolumn{2}{|c|}{ Bodily symptoms } & \multicolumn{2}{|c|}{ Tension } & \multicolumn{2}{|c|}{ Perceived control } \\
\hline & $R^{2}$ & $\beta$ & $R^{2}$ & $\beta$ & $R^{2}$ & $\beta$ & $R^{2}$ & $\beta$ & $R^{2}$ & $\beta$ \\
\hline Step 1: & $.028 * *$ & & .000 & & .014 & & $.035 * * *$ & & $.053 * * *$ & \\
\hline Gender $^{1}$ & & $-.12^{\dagger}$ & & .00 & & -.08 & & $-.15^{* *}$ & & $.13 * *$ \\
\hline $\operatorname{Age}^{1}$ & & .05 & & -.06 & & .01 & & .00 & & -.05 \\
\hline Step 2 & $.113^{* * *}$ & & $.126 * * *$ & & $.107 * * *$ & & $.154 * * *$ & & $.439 * * *$ & \\
\hline Performance-approach goals & & .03 & & -.06 & & -.08 & & -.04 & & .01 \\
\hline Mastery-approach goals & & -.03 & & $-.17 * *$ & & -.06 & & -.01 & & $.21 * * *$ \\
\hline Performance-avoidance goals & & .08 & & $.12^{\dagger}$ & & .04 & & $.16^{*}$ & & -.06 \\
\hline Mastery-avoidance goals & & $.17 * *$ & & $-.19 * *$ & & $.21 * * *$ & & $.20 * *$ & & -.04 \\
\hline General school self-esteem & & $-.19 * *$ & & $-.18 * *$ & & $-.14^{\dagger}$ & & $-.17 * *$ & & $.53 * * *$ \\
\hline
\end{tabular}

Note. $* p<.05, * * p<.01, * * * p<.001, p$-values were adjusted based on the Holm-Bonferroni correction, Gender $($ male $=1$, female $=-1)$.

${ }^{\dagger}$ Values which were statistically significant before Holm-Bonferroni correction

${ }^{1}$ The $\beta$ coefficients from the final regression equation 